\begin{tabular}{|c|c|}
\hline Citation & $\begin{array}{l}\text { Yann Joly, Gratien Dalpé, Charles Dupras, Bénédicte Bévière-Boyer, Aisling } \\
\text { de Paor, Edward S. Dove, Palmira Granados Moreno, Calvin W. L. Ho, Chih- } \\
\text { Hsing Ho, Katharina Ó Cathaoir, Kazuto Kato, Hannah Kim, Lingqiao Song, } \\
\text { Timo Minssen, Pilar Nicolás, Margaret Otlowski, Anya E. R. Prince, Athira P. } \\
\text { S. Nair, Ine Van Hoyweghen, Torsten H. Voigt, Chisato Yamasaki and Yvonne } \\
\text { Bombard (2020), } \\
\text { Establishing the International Genetic Discrimination Observatory } \\
\text { Nature Genetics, }\end{array}$ \\
\hline Archived version & Author manuscript \\
\hline Published version & https://doi.org/10.1038/s41588-020-0606-5 \\
\hline Journal homepage & https://www.nature.com/ng/ \\
\hline Author contact & $\begin{array}{l}\text { Ine.vanhoyweghen@kuleuven.be } \\
\text { your phone number + } 32494574736\end{array}$ \\
\hline IR & l \\
\hline
\end{tabular}




\section{Establishing the International Genetic Discrimination Observatory}

Yann Joly*1, Gratien Dalpé1, Charles Dupras1, Bénédicte Bévière-Boyer2, Aisling de Paor3, Edward S. Dove4, Palmira Granados Moreno1, Calvin WL Ho5, ChihHsing Ho6, Katharina Ó Cathaoir7, Kazuto Kato8, Hannah Kim9, Lingqiao Song1, Timo Minssen7, Pilar Nicolás10, Margaret Otlowski11, Anya E.R. Prince12, Athira P.S. Nair 13, Ine Van Hoyweghen14, Torsten H. Voigt15, Chisato Yamasaki8, Yvonne Bombard16.

*Corresponding author: yann.joly@mcgill.ca

1 Department of Human Genetics, Faculty of Medicine, McGill University, Montréal, Québec,

Canada.

2 Université Paris 8 UFR Droit Saint-Denis, France.

3 School of Law and Government, Dublin City University, Dublin, Ireland.

4 School of Law, University of Edinburgh, Edinburgh, UK.

5 Faculty of Law, The University of Hong Kong, Pok Fu Lam, Hong Kong.

6Academia Sinica, Taipei, Taiwan.

7 Centre for Advanced Studies in Biomedical Innovation Law (CeBIL) \& Centre for Legal Studies

in Welfare and Market (WELMA), University of Copenhagen, Copenhagen, Denmark.

8 Department of Biomedical Ethics and Public Policy, Graduate School of Medicine, Osaka

University, Suita, Osaka, Japan.

9 Asian Institute for Bioethics and Health Law, College of Medicine, Yonsei University, Seoul,

South Korea.

10 Faculty of Law, Chair in Law and the Human Genome, University of the Basque Country,

Biscay, Basque Country, Spain.

11 Centre for Law and Genetics, Faculty of Law, University of Tasmania, Hobart, Tasmania,

Australia.

12 University of lowa College of Law, lowa City, lowa, USA.

13 National University of Advanced Legal Studies, Kochi, Kerala, India.

14 Centre for Sociological Research (CeSO), Leuven Institute for Genomics and Society (LIGAS),

KU Leuven, Leuven, Belgium.

15 Institute of Sociology, RWTH Aachen University, Aachen, North RhineWestphalia, Germany.

16 Institute of Health Policy, Management and Evaluation, University of Toronto. Li Ka Shing

Knowledge Institute, St. Michael's Hospital, Toronto, Ontario, Canada. 


\section{Summary:}

Genetic discrimination is one of the most pervasive challenges resulting from research and development in human genetics. To collaboratively study and prevent this ethical issue, we established an international Genetic Discrimination Observatory comprising a network of researchers and stakeholders from more than 19 jurisdictions.

\section{Commentary:}

In 1997, representatives of 77 national delegations in attendance at the United Nations Educational, Scientific and Cultural Organization's 29 session unanimously adopted the Universal Declaration on the Human Genome and Human Rights. The first article of this fundamental human rights text is probably the best known, stating: "The human genome underlies the fundamental unity of all members of the human family, as well as the recognition of their inherent dignity and diversity."

The Declaration further states, in article 6: "No one shall be subjected to discrimination based on genetic characteristics that is intended to infringe or has the effect of infringing human rights, fundamental freedoms and human dignity."

However, more than 20 years after the adoption of this Declaration, genetic discrimination remains one of the most pervasive concerns identified by the public, patients, scientists, clinicians and research participants worldwide. This discrimination hampers genomic research, precision medicine and the implementation of these technologies for the benefit of people globally $[1,2,3]$.

Discrimination has been defined differently in diverse contexts, such as in law or private insurance, thus potentially explaining why individuals may have different perceptions, expectations and acceptance thresholds concerning this issue [4]. The plain meaning of genetic discrimination usually refers to treating an individual or a group unjustly or prejudicially on the basis of their genetic characteristics [5]. The extent and incidence rate of genetic discrimination remain subjects of debate $[6,7]$, partly because of the difficulty in rigorously assessing these aspects. Cases of genetic discrimination documented in the literature typically focus on the use of test results relating to highly penetrant, severe monogenic diseases in the context of insurance and employment [8, 9, 10]. These cases are likely to represent only the tip of the iceberg, now that both genetic information and nongenetic biomarkers (for example, epigenetic clocks) can be used to predict life expectancy with increasing accuracy [11]; that DNA 
phenotyping models and DNA-methylation panels are considered to be biometric tools in immigration and law enforcement $[12,13]$; and that the prospect of human germline gene editing is becoming a reality [14]. Assuming otherwise would be naïve-there is a very real risk that genetic data and other predictive health data could be used to exclude individuals from opportunities or from participating as equal members of society, rather than to foster our solidarity as collective members of the human species. There are also cases in which genetic information has been used to justify highly questionable discrimination among population groups, classes or genders [15, 16, 17]. Novel challenges are also emerging, given the risk that artificial intelligence may facilitate and propagate bias and discrimination in the processing of genetic information $[18,19]$.

These sobering observations are not meant to deter people from pursuing clinical genetic testing or providing access to their genetic and health data for research purposes. The future of preventive medicine and the improvement of healthcare for all requires a broad flow of genetic data from patients or participants to researchers and clinicians. However, this transfer will not be possible without a complete understanding of the full range of factors and situations that are likely to give rise to genetic discrimination or that may contribute to increased public concerns about its potential occurrence. Therefore, recognizing the urgent need to document and address genetic discrimination is imperative so that the next era of medical science can progress with the full support and trust of the public.

Legal efforts to address genetic discrimination, inspired by international ethics and human-rights texts, should begin at the national or regional level with the implementation of forward-looking, flexible policies promoted by widely accessible information campaigns. Yet, acting solely at this level is unlikely to resolve the problem on its own. First, patients, samples and data, and companies (such as 23andMe, Ancestry.com, MunichRe and Google Cloud) interested in using genetic information are increasingly moving across national borders or transcending them, thus limiting the effectiveness of protections built solely around national approaches. Second, the rapid pace of scientific development, and the challenges in understanding and evaluating the implications of these developments, regularly renders laws obsolete or at least inapplicable to emerging fields of science [3]. After a national law against genetic discrimination is adopted, the technology may have already evolved beyond its scope $[3,20]$, because laws are generally broadly formulated and must follow formal procedures before they are adopted or amended. Other policy models (for example, moratoria, administrative policies, governmental decrees, mandatory ethics regulations, and agreements between organizations and patient groups) may circumvent these shortcomings. Thus, continuing to advance debate and research regarding novel solutions at the national and international levels, by building on both foundational international ethics and human-rights texts, is vitally important.

These reflections led us to assemble an international Genetic Discrimination Observatory (GDO), a unique network of researchers and other stakeholders dedicated to researching and preventing genetic discrimination worldwide. It is forward looking, with a broad purview that includes discrimination based not 
only on genetic information but also on other emerging forms of predictive health data. Its broad approach to genetic discrimination is framed by recognized human-rights principles including respect for autonomy, dignity, privacy, the right to science, and the right to know or not know about genetic results. Stakeholders with diverse backgrounds, experiences and viewpoints will be invited to become involved and share their perspectives on the issue of genetic discrimination through forums, surveys, interviews, workshops and other networking activities. In addition to promoting the expression of individuals and groups with different values, needs and preferences, the GDO will empower them through close and dynamic interaction with experts from a variety of relevant academic disciplines and multiple sectors of industry. Engaging such a broad group of stakeholders will be facilitated by in-person and online events (via Zoom meeting) including scientific meetings, conference panels, online collaborative project platforms and forums, and networking opportunities. Together, participants will be able to collaboratively shape a more inclusive vision of society in which social status, relationships, acquisition of important socioeconomic goods and other meaningful opportunities are not conditional on one's genetic profile.

The GDO online platform, which is available for all to use, will produce information, tools and policy models to help assess and prevent genetic discrimination. All information on the platform will be validated by an international panel representing more than 19 jurisdictions worldwide: Australia, Belgium, Canada, China (including the Hong Kong Special Administrative Region of the People's Republic of China), Denmark, France, Germany, India, Ireland, Japan, Mexico, Republic of Korea, Singapore, Spain, Sweden, Taiwan, United Kingdom and the United States. Lay summaries of domestic policies will also be provided to facilitate public understanding. One example of a tool already provided by the GDO is our real-time geneticdiscrimination map. Our first three maps document (1) existing policy approaches to address genetic discrimination worldwide, (2) studies on the incidence of genetic discrimination in life insurance worldwide and (3) US state laws against genetic discrimination. Members of our international expert group will report on emerging changes in their regions and periodically review all the information that we have on their respective countries to ensure that our maps continue to be up to date. To engage the public in our work, we have developed a special feature called 'report a case', which allows individuals who believe that they have been discriminated against to report their experience so that it can be used-confidentially, securely and with ethics approval-to better document 
the incidence of genetic discrimination in various countries and contexts. Currently, this feature is available in only Canada and the United States because of the need to ensure compliance with the requirements of national jurisdictions before local implementation. However, we hope to be able to open the feature to every jurisdiction represented in the GDO in the years to come. The information obtained through 'report a case' will be expanded more rigorously through harmonized multinational surveys [21] and triangulated with qualitative studies that will use targeted questions designed to mitigate selfreporting bias $[21,22]$. The GDO will also include information directly targeting the public, such as FAQs, a news section, and national and international links to key resources for individuals potentially facing genetic discrimination.

Importantly, after becoming more established, the GDO could also issue public statements and policy guidance on specific matters pertaining to genetic discrimination. Through these tools and features, the GDO will enable researchers with a broad range of expertise in fields such as genetics, ethics, law, sociology and public policies worldwide to work collaboratively with stakeholders to monitor and address developments in genetic discrimination. Although the GDO's headquarters are located at the Centre of Genomics and Policy at McGill University in Montreal, Canada, the headquarters will be moved periodically to allow other countries to assume leadership of this global initiative. Through comparative and interdisciplinary research, the GDO will permit more synchronized and rational policy development at the national level. Through collaborative publications, collaborations with advocacy groups, policy briefs and media op-eds, the GDO will also draw the attention of the international community to developments and trends at the national and international levels, to identify more successful policies against genetic discrimination. It will aim to provide information that neither exaggerates nor downplays the phenomenon, and to empower lay users and stakeholders to address genetic discrimination. Ensuring the long-term sustainability of such an ambitious initiative will be a priority during the early stages of the GDO's existence.

Genetic discrimination has become a loaded term that has polarized stakeholder opinions, thus posing challenges in reaching broad consensus on key questions and finding disinterested funders for genetic-discrimination research. For example, in the field of insurance, the resistance of industry to relinquishing the use of genetic data in their underwriting practices is grounded in the fear of a possible economic risk of adverse selection [23]. In staunch opposition, patient organizations and genetic researchers' objections to this practice are grounded in the need to protect human rights and prevent the effects of genetic discrimination on the uptake of genetic testing (Canadian Coalition for Genetic Fairness) [24] . We hope that, through its broad base of stakeholders and expertise and rigorous evidence-based outputs, the GDO will promote consensus building and appeal to major funding bodies, thus ensuring its long-term sustainability.

Although researchers, scientists, health professionals and patients involved in genetic services agree that genetic discrimination is an important issue [2,25], more sensitive and uniform measures are still needed to evaluate its incidence 
and effects and to develop the right tools to address it. Fear of genetic discrimination clearly has had a negative effect on the uptake of genetic services and research projects $[2,11,26,27,28]$. By developing and promoting the adoption of evidence- based, integrated, policies and tools that address genetic discrimination in multiple jurisdictions, the GDO will contribute to giving individuals the opportunity to use novel genetics technologies without fearing discrimination, thus breathing new life into article 6 of the Universal Declaration on the Human Genome and Human Rights.

\section{Acknowledgements}

We are grateful for the financial support of the PERSPECTIVE I\&I project, funded by the Government of Canada through Genome Canada and the Canadian Institutes of Health Research, the Ministère de l'Économie et de l'Innovation du Québec through Genome Québec, the Québec Breast Cancer Foundation, the CHU de Québec Foundation, the Ontario Research Fund and the FRQ-S/RMGA. The research of T.M. is supported by a Novo Nordisk Foundation grant for a scientifically independent Collaborative Research Programme (grant agreement numberNNF17SA0027784). The authors would also like to thank E. Olvera, F. Brouillet, I. Ngueng Feze, M. Zawati, and present and past members of the GDO Project Team for their help in making this

ambitious project succeed.

\section{Author contributions}

Y.J. developed the concept of the GDO and drafted the manuscript. G.D., C.D. and Y.B. contributed to conceptualizing the GDO. Y.J., G.D., C.D., B.B.B., A.D.P., E.S.D., P.G.M., C.H., C.-H.H., K.O.C., K.K., H.K., L.S., T.M., P.N., M.O., A.E.R.P., A.P.S.N., I.V.H., T.H.V., C.Y. and Y.B. reviewed and edited the manuscript before approving its submission.

\section{Competing interests}

Y.J. and E.S.D. are co-chairs of the Regulatory and Ethics Work Stream of the Global Alliance for Genomics and Health (GA4GH). Y.J. and Y.B. both drafted, acting on their own, independent experts reports in the reference concerning the Canadian Genetic Non- Discrimination Act (2018).

\section{References}

1. Wauters, A. \& Van Hoyweghen, I. J. Hum. Genet. 61, 275-282 (2016).

2. ASHG Executive Committee. Am. J. Hum. Genet. 104, 6-7 (2019).

3. Chapman, C. R., Mehta, K. S., Parent, B. \& Caplan, A. L. J. Law Biosci. x, x-x (2019). 
4. Middleton, A. et al. Eur. J. Med. Genet. 62, 316-323 (2019).

5. Joly, Y., Dupras, C., Pinkesz, M., Tovino, S. A. \& Rothstein, M. A. Annu. Rev. Genomics Hum. Genet. X, x-x (2020).

6. Joly, Y., Ngueng Feze, I. \& Simard, J. BMC Med. 11, 25 (2013).

7. Mohammed, S. et al. Circ Cardiovasc Genet 10, $x-x$ (2017).

8. Bombard, Y. et al. BMJ 338, b2175 (2009).

9. Goh, A. M. Y. et al. Genet. Test. Mol. Biomarkers 17, 115-121 (2013).

10. Smith, R. A., Sillars, A., Chesnut, R. P. \& Zhu, X. Commun. Monogr. 85, 181202 (2018).

11. Dupras, C. et al. Environ. Epigenet. 5, dvz018 (2019).

12. Lee, H. Y., Lee, S. D. \& Shin, K.-J. BMB Rep. 49, 359-369 (2016).

13. Queirós, F. J. Forensic Leg. Med. 68, 101858 (2019).

14. Lander, E. S. et al. Nature 567, 165-168 (2019).

15. Barcelona de Mendoza, V., Huang, Y., Crusto, C. A., Sun, Y. V. \& Taylor, J. Y. Biol. Res. Nurs. 20, 145-152 (2018).

16. Wee, S.-L. The New York Times (2019).

17. Wessel, L. Nature https://doi.org/10.1038/d41586-019-02998-3 (2019).

18. Gianfrancesco, M. A., Tamang, S., Yazdany, J. \& Schmajuk, G. JAMA Intern. Med. 178, 1544-1547 (2018).

19. Parikh, R. B., Teeple, S. \& Navathe, A. S. JAMA 322, 2377-2378 (2019).

20. Dupras, C., Song, L., Saulnier, K. M. \& Joly, Y. Front. Genet. 9, 202 (2018).

21. Wertz, D. C. \& Fletcher, J. C. Genetics and Ethics in Global Perspective 17, (63-71. Springer, Netherlands, 2004).

22. Kelle, U. \& Erzberger, C. A Companion to Qualitative Research (eds Flick, U., Kardorff, E. \& von Steinke, I.) 172-177 (Sage Publications, 2004).

23. Born, P. J. Insur. Regul. 38, x-x (2019).

24. Rothstein, M. A. J. Law Med. Ethics. 46, 794-801 (2018).

25. Bombard, Y. \& Heim-Myers, B. CMAJ 190, E579-E580 (2018).

26. Dalpé, G. et al. Front. Genet. 8, 128 (2017).

27. Robinson, J. O. et al. J. Empir. Res. Hum. Res. Ethics 11, 21-30 (2016).

28. Genetti, C. A. et al. Genet. Med. 21, 622-630 (2019). 